6. Crofts, N. Listeriosis in the UK. Presented at the symposium Listeria and its Implications for Food Safety 1988, Leatherhead, Surrey, UK.

7. Ralovich, B., Forray, A., Mero, E. \& Malovics, H. Additional data on diagnosis and epidemiology of listeria infections. Z Bl Bakt I Abt Orig A 1970, 214: 231-235.

8. Lorber, B. Diagnosis and management of listeriosis. Intern Med 1985, 6: $68-77$.

\section{Recurrent renovascular hypertension in Takayasu's disease}

Sir,

Takayasu's arteritis is an uncommon inflammatory and obliterative process affecting the large and medium sized arteries.' Usually, it is not an aggressive disease. ${ }^{2}$ We describe here one case of Takayasu's disease with surprising tendency to recur.

An 38 year old woman presented with progressive intermittent claudication of the legs. Blood pressure was 220/120 $\mathrm{mmHg}$ and a weak femoral artery pulse was found. Aortography (October 1986) showed severe stenosis of the infrarenal portion of the abdominal aorta and the left renal artery. The patient was referred for surgical correction by insertion of an aortic patch graft and by-pass to the left renal artery. The pathological diagnosis was Takayasu's disease. The hypertension improved partially. Because of poor control of the hypertension a digital subtraction angiography (DSA) was performed (June 1987) and disclosed stenosis of the left renal artery. Another DSA performed because of increasing hypertension (November 1987) revealed stenosis of the right renal artery. A right kidney autotransplant was performed. Hypertension persisted with minimal impairment of renal function. Another DSA performed because of further severe hypertension (February 1988) showed postanastomotic stenosis localized $1 \mathrm{~cm}$ distally to the ostium of the right renal artery resolved successfully with percutaneous transluminal angioplasty (PTA). Another DSA performed (June 1988) because of severe hypertension $(230 / 130 \mathrm{mmHg})$ and impairment of renal function disclosed postanastomotic stenosis of the right renal artery localized $3 \mathrm{~cm}$ distally to the ostium. With PTA this stenosis was again dilated. The patient started steroid therapy and she remains normotensive without antihypertension drugs and with no impairment of renal function.

Takayasu's aortitis is classically considered a process with an initial period which precedes another period of obliterative vascular disease that is slowly progressive. ${ }^{3.4}$ In the present case, Takayasu's aortitis appears as an aggressive disease with three recurrences after successful therapeutic manoeuvres. This recurrent form is a very unusual pattern in Takayasu's disease.

J.L. Reverter

R. Lauzurica

J. Bonal

A. Caralps

Hospital de Badalona.

Carre de Canyet s/n 08916, Badalona, Barcelona,

Spain

\section{References}

1. Lupi-Herrera, E., Sánchez-Torres, G., Marcushamer, J., Mispireta, J., Horwitz, S. \& Espino-Vela, J. Takayasu's arteritis. Clinical study of 107 cases. Am Heart J 1977, 93: 94- 103.

2. Fraga, A., Mintz, G., Valle, L. \& Flores-Izquierdo, G. Takayasu's arteritis: Frequency of systemic manifestations (study of 22 patients) and favorable response to maintenance steroid therapy with adrenocorticosteroids (12 patients). Arthritis Rheum 1972, 15: 617-623.

3. Ask-Upmark, E. On the 'pulseless disease' outside of Japan. Acta Med Scand 1954, 149: 161-178.

4. Ishikawa, K. Natural history and classification of occlusive thromboaortopathy (Takayasu's disease). Circulation 1978, 57: 27-35. 